\title{
Study of the Nature of Modern Economic Crises
}

\author{
Gennady V. Ross \\ Department of System Analysis in Economics \\ Financial University under the Government of the Russian \\ Federation \\ Moscow, Russian Federation \\ Vladimir E. Liechtenstein \\ Department of System Analysis in Economics \\ Financial University under the Government of the Russian \\ Federation \\ Moscow, Russian Federation
}

\author{
Alena V. Fomina \\ JSC "Central Research Institute of Economy Management \\ and Information Systems "Electronics" \\ Moscow, Russian Federation \\ Elena G. Semenova \\ Institute of Innovation and Master Basic Training \\ Saint-Petersburg State University of Aerospace \\ Instrumentation \\ Saint-Petersburg, Russian Federation
}

\author{
Victor M. Balashov \\ JSC «Scientific and Production Enterprise "Radar MMS"» \\ Saint-Petersburg, Russian Federation
}

\begin{abstract}
A model of capital flows is proposed in this article and it is shown herein that the natural result of this flow is the emergence of the information collapse of the second type, the essence of which is that the transmitted economic information becomes distorted, which results in the loss of controllability. This is the essence of modern economic crises. The role of financial bubbles in the onset of collapse is shown. The size of the bubble in the American economy is estimated. The signs of the onset of collapse of the second kind are given. The concepts of the market mechanism and the planned mechanism as well as the ways of switching between them as a means of preventing crisis phenomena in the economy are considered.
\end{abstract}

Keywords-financial bubbles; capital flows; crisis; management of the economy.

\section{INTRODUCTION}

There are quite definite answers to the questions related to the sources of tendencies observed in the modern world economy. And, importantly, these answers are direct consequences of mathematically rigorously established facts, namely the theorems proved in the framework of the theory of equilibrium random processes (ERP) [9]. The theorems imply that, firstly, if one keeps out of what is going on, then the world economy will turn into one big financial bubble, and secondly, the purely market methods are unable to correct the situation; thirdly, the purely planned methods are also unable to correct it. Moreover, importantly, the theorems indicate the ways out of the impasse, albeit in the most general terms.

In this article, the authors make the attempts to consider all these issues in succession and, if possible, briefly. It should be emphasized that we are discussing exclusively and only the economic system and do not concern the state structure of any countries and do not try to make political forecasts. So, for example, when we say that the USA is turning into a financial bubble, which is about to burst, we do not want to say that we predict the collapse of the country, a coup or a civil war in the USA. We are talking about the necessity and inevitability of a profound reform of the world economic system, in other words, about changing the rules of the economic game. Many have already come to this conclusion, independently of us. Our innovation lies in the fact that we rely on mathematics and provide the irrefutable arguments not only in favor of the need to change the rules of the game, but also establish some fundamentally important, mandatory directions for these changes. In particular, the economic measures as well as the economic management by the nation states require the radical improvement. A methodology, technology, and a system of adjustments should be developed to remove the distortions brought about by the financial bubbles. Without this, any interstate comparisons are meaningless, and the economic relations of the states are unfair. Moreover, the nation states should also have among the instruments of economic management those that allow the switching of the market mechanisms (MM) to the planned mechanisms (PM) and vice versa without violating the private property rights.

In this article, the problem of changing the rules of the economic game is formulated constructively, while the possible solutions to it are only mentioned, bearing in mind that the monographs $[8,9]$ of the authors contain a detailed consideration of them.

This problem is widely discussed in the scientific literature. The main fields of study on the problem of threats to the world economy are represented, for example, in the works $[4,5,11$, $12,13]$. The problems related to the levels of transparency of the economies are considered in the work of Kaurova [4]; Kobyakov and Khazin [5] 6 study in detail the role of high technology in the world economy; Soros [11] analyzes some sources of global threats deriving from the motives of behavior of the market participants. The growing role of psychological factors and related threats are considered in the scientific works 
of Becker [12], awarded with the Nobel Prize in 1992. The role of electronic commerce for entrepreneurial business orientation is considered in the article of Abebe [13]; the role of contractual relations and the financial aspects of international trade are studied in the articles of Beamish [14] and Beck [15], respectively.

\section{MODEL OF CAPITAL FLOWS}

In order to discover the primary source of the main problems of the world economy and to disclose their internal laws, let us imagine the economy as a set of economic agents, namely, enterprises that exchange goods (services and financial resources will be considered as the varieties of goods). The internal structure and specialization of the agents are irrelevant to us. Enterprises plan their activities and exist in a random environment. This means that their functioning is an equilibrium random process (ERP). By definition: "An equilibrium random process (ERP) is a process the trajectory of which in the phase space is determined by a combination of random factors and control actions, the direction and the force of which are determined by the size and direction of the deviation of the actual trajectory from the smoothed one" [9]. The ERP was discovered by the authors hereof. The authors also developed a methodology for the mathematical simulation of ERPs, namely the Evolutionary Simulation Methodology, and the instrumental system for making optimal decisions under the conditions of uncertainty and decision risk [8], which allows the software to implement the Evolutionary Simulation Models (ESM) $[1,3,6,7,10]$.

In order to describe the economic laws of interest to us and the theorems mentioned, we need several fundamental concepts of the ERP theory, in particular: the risk of overstatement, the risk of understatement, the equilibrium of risks, reliability, etc. The relations (1)-(9) represent a structural linear formulation of ESM, which gives the concepts we need a completely certain meaning and link them to the system.

$$
\begin{aligned}
& F a^{e}=k_{0}+\sum_{i} f_{i}^{e} k_{i} \\
& \Psi_{1}\left(P L, F a^{e}\right)=S\left(P L-F a^{e}\right), i f \quad P L>F a^{e} \\
& \Psi_{2}\left(P L, F a^{e}\right)=(C-S)\left(F a^{e}-P L\right), \\
& \text { if } \quad P L<F a^{e} \\
& \min _{P L}\left\{\max _{L \in\{1 ; 2\}}\left\{M\left\{\Psi_{L}\left(P L, F a_{L}\right)\right\}\right\}\right\} \\
& P^{0}=P(P L>F a) \\
& O / U=\frac{S}{C-S} \\
& Z=\frac{C-S}{S}=\frac{1}{O / U} \\
& D=Z \cdot P^{0} \\
& K=C \cdot P L
\end{aligned}
$$

In (1) $f_{i}^{e}$ is a scalar random variable, representing the random influence of the environment on the agent, such as fluctuations in prices, incomes of buyers, their intentions, etc. The lower index i numbers the factors in order, and the upper index e indicates that the formula includes the realization of the factor, obtained in the statistical test, carried on with the help of the corresponding modeling factor of the computational algorithm. The linear regression coefficients $k_{0}, k_{1}, k_{2}, \ldots$ link the factors in such a way as to calculate the realization of the agent's integral characteristic, namely the aggregate volume of the product $F a^{e}$ produced by the agent. If we assume that the enterprise produces a mono-product, then $F a^{e}$ is the implementation of the volume of demand for the goods produced by the enterprise in natural units.

PL represents the plan for delivering goods to the market for the forthcoming period. When drawing up the plan, the enterprise is guided by the ratio of the risk of overstatement $M\left\{\Psi_{L}\left(P L, F a_{L}\right)\right\}($ at $\mathrm{L}=1)$ and the risk of understatement $M\left\{\Psi_{L}\left(P L, F a_{L}\right)\right\}($ at $\mathrm{L}=2)$, where $\mathrm{M}$ is a symbol of mathematical expectation. These risks are the mathematical expectations of the costs of overstatement $\Psi_{l}\left(P L, F a_{1}\right)$ and the costs of overstatement $\Psi_{2}\left(P L, F a_{2}\right)$ respectively. For an enterprise, supplying a mono-product, the meaning of the costs is quite obvious: if the company has put on the market PL units of goods, but managed to sell less, that is, if $P L>F a^{e}$, then the goods in the volume of $\left(P L-F a^{e}\right)$ will not be sold.

The cost price of the goods produced, but not sold $S\left(P L>F a^{e}\right)$ (especially if the goods are perishable), is the costs of overstatement, where $S$ is the cost price of a unit of goods. This can be represented by the formula (2). The cost of understatement, reflected by the formula (3), is the lost profit in the amount $(C-S)\left(F a^{e}-P L\right)$ that occurs in a situation

$P L<F a^{e}$ where the demand is greater than supply, where $\mathrm{C}$ is the price of goods.

The formula (4) represents the behavior of the agent: on the one hand, one is afraid of losing the profits, and on the other one is afraid of losing the funds. This results in the psychological forms of expression of the risks of overstatement and understatement, respectively, the presence of which contributes to navigation in the market situation. The condition (4) represents the desire to minimize the greatest of the risks. The condition (4) can be written equivalently as follows:

\section{Risk of overstatement $=$ Risk of understatement .}

The equality of the risks unambiguously determines the plan for the delivery of goods to the PL market. The formulas (6)(9), in turn, define several characteristics of the ERPs that are interdependent with the PL plan: $P^{0}$ - the probability of PL plan execution and, at the same time, the reliability of transactions of the enterprise; $O / U$ - the ratio of the risk of overstatement to the risk of understatement; $Z$ - average specific yield; $D$ - average specific yield taking the risk into account; $K$ - capitalization. 
$\mathrm{O} / \mathrm{U}$ is the linear approximation of the relation $\frac{M\left\{\Psi_{1}\left(P L, F a_{1}\right)\right\}}{M\left\{\Psi_{2}\left(P L, F a_{2}\right)\right\}}$ in the vicinity of PL.

Let us consider the economic system in the initial situation, in which all enterprises are absolutely equal in economic terms. Let this economic system be able to operate without any external interference. In the ideal (and, moreover, in the real) economy under consideration, according to the theorems proved [9], the following will occur:

- $\quad$ there will be a division of the agents by the value of $\mathrm{D}$ and by the capitalization of $\mathrm{K}$;

- the capital will flow from those agents, where D is less, to those where $\mathrm{D}$ is greater;

- the amount of financial flow between the agents will be proportional to the difference in the values of $\mathrm{D}$, in turn, $\mathrm{D}$ and $\mathrm{K}$ will grow monotonously as a result of the capital flows;

- the reliability of P0 transactions will increase in those agents where $\mathrm{K}$ is larger and decrease in those where $\mathrm{K}$ is smaller;

- the criterion of optimality: $D \rightarrow \max$ will become total, since every economic agent will have to use it as reference, and global, because the economic system as a whole will use it as reference.

It should be noted that if one considers the agents of a different nature instead of the economic agents, for example, a population of living cells or microorganisms, a set of robots with interaction rules similar to those of the economic agents by a limited set of characteristics, then the same processes will be observed. Thus, on the basis of proven theorems, the technologies for modeling the life activities of biocenoses, the differentiation and specialization of the organs, and the systems for managing the totality of robots and other multi-agent systems (MAS) can be built.

\section{INFORMATION COLLAPSE OF THE SECOND TYPE}

In theory, it happens as it is mentioned above. In real life, exactly the same thing happens, if we take into account the global scale and a sufficiently long, at least several years, interval of time. Even a very common and greatly simplifying assumption that the economy consists of enterprises that are not interested in anything other than money, is being carried out more accurately, more precisely for those enterprises the D of which is greater. In real life, the methods for maximizing D are numerous and diverse. Of course, the cost of production can be reduced, the quality of products can be improved, the supply can be increased. These variants are the most labor-intensive and, consequently, the furthest from the optimum options for behavior by $D \rightarrow \max$ criterion. The easiest, the optimal way of increasing $\mathrm{D}$ by $D \rightarrow \max$ criterion is the blowing up of the financial bubble and keeping the bubble safe from "blowing out." It is the saving of the financial bubbles that is the most important symptom and the clear sign of the crisis.

For these reasons, the processes of differentiations and imbalances in the world economy are increasing steadily. In other words, the capital is concentrated in a limited and increasingly reducing number of agents, the D which is the greatest. Their D increases steadily, while the D of others decreases. Only one enterprise remains within the limit that collects all the capital and the functioning of the system ceases. The economy dies! Immediately we note that in a real economy, where the agents are not identical, when they produce a variety of goods instead of a mono-product, but where the corruption, money laundering and the desire for dominance take place, these processes are not restrained, but spurred on.

All this is quite definitely observed in the modern economy. The circle of the richest is narrowing, while their wealth is increasing. According to the international association of 17 Oxfam organizations, globally "the richest $1 \%$ bagged $82 \%$ of the wealth created last year; the poorest half of humanity got nothing." In order to understand the conceptual meaning of the reduction of the reliability of $\mathrm{P} 0$, let us refer to the notion of the information collapse. Usually, the information collapse is understood as a sharp decrease in the capacity of communication or transport channels, which the existing infrastructure cannot cope with. We call it the collapse of the first type and introduce the concept of a collapse of the second type, the essence of which is in the unreliability or distortion, or noise contamination of the transmitted information.

The approximation of P0 to 0 in most economic agents means that the economic information, especially the information carried by prices, is highly distorted by the financial bubbles, monopoly premiums, postscripts and false advertising. On the basis of P0, we give the following definition: the information collapse of the second type is the state of a multiagent system (MAS), in which the reliability of the information $\mathrm{P} 0$ exchanged by the agents has decreased to a level that threatens its stability, normal functioning, selforganization or development. This definition encompasses the MAS of any nature and identifies the specifics of the information exchange infringements that occur according to the laws that operate within the MAS. The onset of the collapse of the second type is equivalent to the onset of chaos. From the theorems proved, it follows that the information collapse of the second type and the chaos are the fatal end to the selforganization and development of the MAS of any nature. This is one of the most unexplained causes of mortality of living organisms, biocenoses and the economy.

The information collapse of the second type makes the traditional market economy, which according to Soros is the economy of the "free world" [11], unviable!

\section{FINANCIAL BUBBLES}

Modern legislation of different countries and new information technologies, methods of advertising, create many different ways of blowing up and keeping safe the financial bubbles and spreading the domination by the largest enterprises, that is, those with the greater D. Let us refer to some characteristic ways of blowing up the world's largest financial bubble - the American one. "The composition of the US GDP includes also the so-called attributable rent - the rent that the owners of houses and apartments should have to pay if they lived in rented housing. That is, the GDP includes a nonexistent rent, which American citizens "pay" themselves to themselves. Most other countries do not include the attributable 
rent in the GDP. At the same time, it is estimated that it amounts to $10 \%$ of the US GDP. And this is much more than the GDP of many countries" [5].

At the same time, many experts treat the attributable rent as a very effective measure and give arguments that at first glance it seems convincing. So, there is an opinion that the attributable rent is a way of active use of real estate for the purposes of obtaining the loans on bail. Simply put, an apartment in Russia is a liability, and an American apartment is an asset: it is mortgaged and re-pledged. This money is used to buy shares, which not only bring dividends, but help to invest in science, in its breakthrough directions. Hence, it is concluded that when calculating the GDP, it is required to take into account not the added value, which is generally accepted, but the sales volume, as the US actually does. Among other things, the attributable rent incites the resale of goods that are American only legally, although they are physically manufactured in other countries, in particular, in China. This gives the US a competitive advantage, as it improves the ratio of the value-added cost and the prices compared to other countries. For example, the higher the salaries and prices, the better such indicators as labor productivity, profit and others compared with those countries where the level of prices is lower, although the technology is the same, and sometimes better. For example, if a gadget produced in China is sold in the USA, then the share of the Chinese manufacturer in its value is small, and the share of the American seller is much higher.

Let us consider the reliability of the pledge mechanism of attraction of assets. The interest is accrued with each pledge. As a result, 1 initially provided ruble turns into a large number of little-secured money. This is one of the endless variety of forms of the existence of a financial bubble. The money from the bubble mostly goes into circulation, and in accordance with the main statement of the founder of monetarism, Nobel Laureate M. Fridman: the amount of money in circulation is the determining factor in the development of the economy. But the disadvantage of this system is that its well-being continues exactly as much as the bubble or, what is the same, the pyramid, is being persisted and blown up. As the bubble is global, it is blown up slowly.

To estimate roughly the share of the bubble in the US GDP, one can assume that it is roughly equal to the dollar bubble and compare the amount of dollars needed to ensure the commodity circulation around the world (that is, the amount of dollars provided by the commodity mass) with the total number of dollars circulating in the world. It turns out that the bubble occupies about $97 \%$. This figure arises from the comparison of the US derivatives market (about 710 trillion USD in 2014) and the dollar trade turnover in the world on average per day, roughly equal to the Forex market turnover of about $\$ 5$ trillion. Therefore, $0.7 \%$ are enough to ensure the commodity turnover. Actually, a somewhat larger amount is needed, since some transactions take significantly more time than one day. Given this, as well as the statistical errors and the errors caused by the timing of the estimates, the upper limit of the need for dollars for commodity circulation is estimated at 3\%. Another way of estimation of the bubble share may be based on a comparison of the purchasing power parities of different currencies. This method gives approximately the same $97 \%$.
The United States has another important advantage - high technology. An opinion is expressed that Chinese production is impossible without American technology. It turns out, however, "... that the companies of the "new economy," that is, the hightech sector, which are considered to be the vanguard of the American economy, are greatly overvalued. This situation is of anecdotal, not to say delirious, nature. The figures are simply astronomical: according to the NASDAQ market, the capitalization in the $1990 \mathrm{~s}-2000$ s exceeded the net profit more than 200 times, and for individual companies, for example, for the Internet company Yahoo!, this indicator was equal to 1200 or more. The true meaning of this figure can be understood if you try to imagine an individual investor who wants to buy the company entirely at the current market price, in other words, who agreed to acquire an asset that will pay off only in 1200 years! The absurdity of this assumption is obvious" [5]. Blowing the bubbles up is the most effective investment. More precisely, investments in financial turnover have the highest average specific return taking into account the D risk. Therefore, the capital flows from the real sector to the financial one. And the investments in science are long-term, risky and not very profitable [16]. As a result, high technologies are replaced by bubbles. It is much more effective to buy up the patents for a pittance, than to invest in science. Approximately so do the largest high-tech companies. The share of the financial bubble in the capitalization of high technology is probably the largest of all other fields of investment. Thus, the criterion prevails over the knowledge economy, in which goods are the know-how, the property for which is established by the patents, licenses and contracts. This can be expressed in the form of 3 main trends:

(1) first, in the mass purchase of patents and licenses by the largest corporations and the desire of the big capital to dominate through the creation of convenient licensing and patenting rules (for example, the extension of the US jurisdiction to other countries);

(2) secondly, in the transformation of know-how owners into rentiers with no incentives for other activities, except for the capital attraction;

(3) thirdly, in transferring of the capital from the scientific, as well as industrial and in general, any other activity, to the financial one, the export of the production from its own country in order to use cheap labor.

As a result, the "knowledge economy" and, in general, the "new economy" has a downward multiplier [5].

Another fundamentally important problem related to the bubbles implies from the fact that money is the bearer of the economic information. All derivative economic indicators (income, profit, GDP, etc.) are based on the prices. With the growth of bubbles, the prices lose the connection with the reality. At the same time, financial bubbles systematically, totally and globally distort the information. The reliability of the economic information is $P^{0} \approx 3 \%$. This is the essence of the information collapse of the second type, to which the world economy is approaching. Currently, the "finances have broken away from the economic basis and began to play a fundamental role in socio-economic relations, enlarging the gap between the material-monetary and financial flows. The financial system 
and financial capital have been transformed from an intermediary servicing reproduction to a key factor that determines it" [4].

It can be said that financial bubbles appeared together with money and arose mainly on the basis of the formation of the speculative demand. The tulip bubble is the first historically reliably described bubble and it was included in the textbooks on the stock-exchange industry. During the three years preceding the "collapse" of the flower bubble, the price of tulips grew at a tremendous rate, having increased more than a hundredfold. The increase of the price by creation of speculative demand, active advertising, creation of a brand, etc. is a systemic way of inflating a bubble, because the signs of such a bubble cannot be found either in the financial statements of the enterprises, in the government statistics, in the legislative violations, or in the surveys of sellers or buyers. The purchases are made voluntarily. New information technologies give this method of inflating bubbles new opportunities. New opportunities and new dangers arise due to the emergence of crypto-currencies. On the one hand, Blockchain technology opens up new opportunities for the reliable, confidential implementation of transactions and other operations without intermediaries.

\section{THE LACK OF KNOWN METHODS FOR STATE MANAGEMENT OF THE ECONOMY}

The fact that under the conditions of collapse of the second type only a very limited number of economic agents have maximal PL, K and D means that they: supply to the market as much of PL goods as is achievable at its production facilities; own almost all the available capital $\mathrm{K}$; all their operations have the highest possible yield $\mathrm{D}$; the success of any transaction they conduct is almost guaranteed $\left(P^{0} \approx 1\right)$. However, all other economic agents have the opposite: they do not supply anything to the market ( $\mathrm{PL}$ is minimal), they have almost no capital ( $\mathrm{K}$ is minimal), almost all their transactions have the lowest possible yield $\mathrm{D}$, and each transaction is almost always unsuccessful ( $\left.P^{0} \approx 0\right)$.

The criterion $D \rightarrow \max$ extends to all spheres of human activity. Nobel Laureate G.S. Becker notes that the economic approach extends to all human behavior, the motivation of all actions, subordinating everything solely to material, more precisely, to financial benefits. "It is about the claim that "the economic approach is comprehensive, it applies to all human behavior. ... The economic approach proposed by Becker allowed a different look at many old problems. For example, the desire for education is not only a valuable desire for knowledge, but also the most profitable way of investing: the costs of education increase the ability to make a living (this is the very "human capital"), and this method of taking care of future incomes is much more effective than buying shares or other investments in ordinary "physical capital." According to Becker, the criminals are not "monsters of the human race," but quite rational people who consider breaking the law as the most profitable business for them. In our opinion, this is a natural and inevitable consequence of the totality and globality of the criterion $D \rightarrow \max$.
Along with the bubbles, the persons interested in preservation of the bubbles emerge. The lobbyists in the legislative, monetary and executive bodies of the state protect and preserve the financial bubbles. The proved theorems [9] imply that the economy cannot be preserved by the measures of state regulation that are not limited in time or unrelated to the situation:

- $\quad$ if the state tries to impose the production plans on the agents, then the disproportions between them will be transferred to the nomenclature of goods produced, that is, there will be a deficit of some goods and the excess stocks of others;

- $\quad$ if the state tries to keep the prices for the goods of any agent, then the suppliers will be replaced;

- if the state equalizes the working conditions of different agents (for example, to compensate for the costs at public expense), then the inefficiency will be preserved and there will be a flow of capital from the efficient agents to the inefficient ones.

Thus, the planned socialist economy is not viable also.

Methods for estimation of the financial bubble share (FBS) can take into account the characteristics of the economic agents and are of fundamental importance in interstate comparisons, business valuation, antimonopoly measures and in many other cases. The evolutionary-simulative models of specific economic agents make it possible to calculate the reliabilities P0 characteristic to them. Since the reliabilities P0 are universally comparable, different methods of estimation of the FBS can be constructed on this basis.

The central problem of the ideology of the future economy is the problem of the relationship between the state and the market. Without opposing itself to the market, the state serves to save the economy from the criterion $\mathrm{D} \rightarrow \max$. This criterion should be replaced by the requirement of economic justice, for which D should be approximately equal for all economic agents. This also ensures a reduction in the economic measurement errors, in particular, a decrease in the FBS. At the same time, we are not talking about maintaining the strict equality of $\mathrm{D}$ in an ideal and continuous manner. In this case, any movement of capital will cease, the incentives for improvement of the production will disappear, and the distribution of the resources will be frozen. In this connection, the question of what the economy lacks is divided into two questions: In what situations should the state interfere to equalize D? and What tools should be used for this purpose? To answer these questions, the notions of a planned mechanism $(\mathrm{PM})$ and a market mechanism $(\mathrm{MM})$ are required $[3,7,9]$.

\section{NEW METHODS OF STATE MANAGEMENT}

The PM is understood herein as the mechanism of management, acting on a specific sector of the market, based on the fact that the volume of sales or the price, or both of them are established in the form of reference figures, and the economic incentive system provides for the fines and incentives, depending on the size and orientation of the actual deviation values from reference figures, and the $\mathrm{MM}$ is the mechanism of spontaneous determination of the sales volume and the prices, proceeding from the ratio of demand and supply. A 
fundamentally important feature of the PM and the MM is that the state has the opportunity to switch from the MM to the PM and vice-versa in any sector of the market for any period of time, without violating any property rights. The MM and the PM can simultaneously work in different sectors of the market.

The MM is required to reveal the real prices, supply and demand, intentions of producers and consumers, distribution of resources. The PM, in turn, allows the state to eliminate the disproportions, to destroy the bubbles, and to solve social and strategic tasks. The inclusion of the PM is an instrument of state intervention. To adjust this instrument and to answer the question "When to interfere?", the evolutionary-simulative models of the MM, the PM and the economic agents should be developed. It should be emphasized that Russia today has all the necessary prerequisites to become the world leader in the economic construction.

The state management performed through switching from the MM to the PM makes it possible to deal efficiently with a variety of tasks, such as selection of an appropriate degree of transparency of the economy, which “... must comply first and foremost the level of competitiveness of the national economy, as well as its role and contribution (determined by the GDP level) to the total volume of world exports of goods and services" [4]. The degree of transparency, in turn, is associated with the independence of the national currency. For most states, this is possible only in case of existence of several world reserve currencies.

\section{CONCLUSION}

In general, the economy of the foreseeable future looks as follows: there must be a market core, consisting of market sectors, based on which it is possible to maintain the conditions for perfect competition. The market core should be in an environment of the state planned management. The market core is the physical agent that is held within the required framework. The boundaries of the market core are mobile, "breathing." They are established by the state in accordance with the current situation according to the objective criteria, which are developed on the basis of proven theorems using the evolutionary-simulative methodology (ESM). The information systems for monitoring the situation, establishing the periods of action of the MM and the PM in different sectors of the market, the selection of the parameters of the economic incentive and taxation systems can be created on the basis of the ESM using the Decision $[1,2,6,7,10]$. By transferring this or that sector of the market to the $\mathrm{MM}$, the state receives the information, and by transferring it to the PM, it uses it for management. In the absence of sufficient grounds, the state should transfer the sector to the market core.

\section{References}

[1] M.G. Bich, "International experience of the conclusion of civil-legal electronic transactions," Telecommunications and Transport, Special Issue, July 2009.

[2] V.A. Deeva (Ed.), Management of Equilibrium Random Processes in Financial Markets. Moscow: Yurisprudentsiya, 2007.

[3] I.N. Drohobytsky, System Analysis in the Economy. Moscow: Finansy i statistika, 2007.
[4] N. Kaurova, Financial and Economic Security in Conditions of Transparency of the National Economy (Theoretical and Methodological Aspect). Moscow: IE RAS, 2013.

[5] A. Kobyakov and M. Khazin, The Decline of the Dollar's Empire and the End of the "Pax Americana". Moscow: Veche, 2003.

[6] S.G. Lalaev, "Amortization premium as a factor of economic growth," Finance, vol. 7, 2008.

[7] S.G. Lalaev, "Analysis of information technologies for solving optimized economic problems," in: Proceedings of the ISPM "Informatization and Globalization of Social and Economic Processes". RSUH, 2007.

[8] V.E. Liechtenstein and G.V. Ross, Information Technology in Business. Application of the Decision System in Micro- and Macroeconomics. Workshop. Moscow: Finansy i statistika, 2008.

[9] V.E. Liechtenstein and G.V. Ross, Equilibrium Random Processes: Theory, Practice, Infobusiness. Moscow: Finansy i Statistika, 2015.

[10] S.V. Mukin, "Evolutionary-simulational method of regional management," Socio-Economic Phenomena and Processes, no. 7-8 (4142), pp. 111-117, 2012.

[11] D. Soros, Alchemy of Finance. Moscow: INFRA-M, 1997.

[12] G.S. Becker, S.D. Kominers, K.M. Murphy, and J.L. Spenkuch, A Theory of Intergenerational Mobility, MPRA Paper No. 66334, August 2015.

[13] M. Abebe, "Electronic commerce adoption, entrepreneurial orientation and small- and medium-sized entreprise (SME) performance," Journal of Small Business and Enterprise Development, vol. 21, no. 1, pp. 100-116, 2014.

[14] P.W. Beamish, "The role of alliances in international entrepreneurship," Research in Global Strategic Management, vol. 7, no. 1, pp. 43-61, 1999.

[15] T. Beck, "Financial development and international trade: is there a link?," Journal of International Economics, vol. 57, no. 1, pp. 107-131, 2002.

[16] A.M. Batkovskiy, A.V. Konovalova, E.G. Semenova, V.Y. Trofimets, and A.V. Fomina, "Risks of development and implementation of innovative projects," Mediterranean Journal of Social Sciences, vol. 6, no. 4, pp. 243-253, 2015. 